\title{
Hot Ductility and Deformation Behavior of C-Mn/Nb-Microalloyed Steel Related to Cracking During Continuous Casting
}

\author{
H.A. Lanjewar, Pranavkumar Tripathi, M. Singhai, and P.K. Patra
}

\author{
(Submitted April 16, 2014; in revised form June 14, 2014; published online July 18, 2014)
}

\begin{abstract}
Hot ductility studies have been performed on C-Mn and C-Mn-Nb steels with an approach to simulate the effect of cooling conditions experienced by steel in secondary cooling zone during continuous casting. Thermal oscillations prior to tensile straining deteriorate hot ductility of steel by deepening and widening the hot ductility trough. C-Mn steels are found to exhibit ductility troughs in three distinct zones whereas $\mathrm{C}-\mathrm{Mn}-\mathrm{Nb}$ steel shows drop in ductility only at low temperature in the vicinity of ferrite transformation temperatures. Start of ferrite transformation in steels causes yield ratio to increase while work hardening rates and strength coefficient decrease with decrease in test temperature in presence of thermal oscillation prior to tensile testing. Inhibition of recrystallization due to build-up of AIN particles along with the presence of MnS particles in structure and low work hardening rates causes embrittlement of steel in austenitic range. Alloying elements enhancing work hardening rates in austenitic range can be promoted to improve hot ductility. The presence of low melting phase saturated with impurities along the austenitic grain boundaries causes intergranular fracture at high temperature in C-Mn steels.
\end{abstract}

Keywords cracking in continuous casting, deformation behavior, hot ductility

\section{Introduction}

Continuous casting is the most widely used manufacturing method to process liquid steel owing to reduced operation cost, improved product uniformity and quality. However, continuous cast products suffer from surface defects which can be attributed to the complex thermal and mechanical stresses developed in cast section; and aspects of mechanical behavior of steel in the continuous casting process. Defects like longitudinal and transverse corner cracks, longitudinal and transverse face cracks, internal tears, etc., may result owing to stress- or stain-induced on account of thermal strains and bending strains during plastic bending ( $\operatorname{Ref} 1,2)$.

Hot ductility tests on laboratory scale have been a very useful tool in determining crack susceptibility of steel at various temperatures prevailing during continuous casting operation. Conventional hot ductility tests consist of solution-treating the steel to dissolve all the alloying and grain refining additions and to produce sufficiently coarse grain structure. Post-solutionization test consists of cooling specimen to the test temperature

H.A. Lanjewar and Pranavkumar Tripathi, Research \& Development and Scientific Services, JSW Steel Ltd., Vijaynagar Works, Toranagallu, Bellary, Karnataka, India; and M. Singhai and P.K. Patra Research \& Development, JSW Steel Ltd., Dolvi Works, Raigad, Maharashtra, India. Contact e-mails: harish.lanjewar@gmail. com, pranavkumar.tripathi@jsw.in, mrigandra.singhai@jsw.in, and pradip.patra@jsw.in. 
temperature have been recommended. For steels with wider ductility trough behavior, small differences in ductility between specimen given oscillations and those without, would not justify application of such complex thermal profiles. Hence, in the present study, conventional hot ductility tests have been applied to test the specimen at different temperatures. Since, undercooling step before tensile straining at test temperature leads to deepening and widening of ductility trough, it has been incorporated in the thermal cycle, simulating the effect of extreme cooling conditions experienced by steel during secondary cooling in continuous casting.

In previous studies, little effort has been put to correlate the hot ductility observed in steel with its mechanical behavior at high temperature which can assist in determining the causes of embrittlement in steel at different stages of solidification. The objective of the present investigation is twofold:

(i) To understand fracture mechanisms associated with the hot ductility at different temperatures.

(ii) To correlate hot ductility with high temperature mechanical/deformation behavior of steel and highlight the causes of steel embrittlement.

\section{Experimental}

Cylindrical steel samples of length 121.5 and $10 \mathrm{~mm}$ diameter were machined from $50 \mathrm{~mm}$ cast thin slab with longitudinal axis of sample aligned along the casting direction. The chemical composition of the steels investigated is as given in Table 1. Two types of steels were undertaken in present study, viz. C-Mn steel and C-Mn-Nb-microalloyed steel. The schematics of the different thermal cycles applied to different steels are shown in Fig. 1. Steel 1 was tested using conventional hot tensile test; while in order to study the hot ductility deterioration owing to undercooling and reheating cycle, Steel 2 and 3 were given an undercooling step before reheating to the test temperature. C-Mn steels were solution treated at sufficiently high temperature, i.e., $1400{ }^{\circ} \mathrm{C}$ for $30 \mathrm{~s}$ to dissolve all the $\mathrm{MnS}$ and AlN particles and generate coarse grain structure. As a result, grains of the order of millimeter size were observed in steel samples with worst ductility. $\mathrm{Nb}$-microalloyed steel was solutionized at $1300{ }^{\circ} \mathrm{C}$ for a longer duration, i.e., 2 min to attain complete dissolution of $\mathrm{Nb}(\mathrm{CN})$, and AlN particles. Hot ductility tests were performed at various temperatures ranging from 700 to $1400{ }^{\circ} \mathrm{C}$. After solution treatment, Steel 2 and 3 samples were rapidly cooled to $T_{\text {min }}$ which was $100{ }^{\circ} \mathrm{C}$ below the test temperature and a constant strain rate of $5 \times 10^{-3} \mathrm{~s}^{-1}$ was used for tensile deformation. Vacuum environment was maintained during entire testing to avoid any scale formation.

Hot ductility tests were conducted in Gleeble 3800 thermomechanical simulator. Hot steel grips with free span of $25 \mathrm{~mm}$ were used to hold and heat the test specimen using resistance heating. Use of these grips helped in maintaining uniform temperature within the free span zone and thus ensuring tensile failure at the center of the test specimen. Temperature measurement and control was done through $\mathrm{Pt}-\mathrm{Pt}+13 \% \mathrm{Rh}$ thermocouple, spot welded on to the sample surface.

Fractured surface characterization was performed using scanning electron microscope, and EDX was used to perform compositional analysis of precipitate particles on fractured surfaces. Tensile straining data obtained from Gleeble were used for analyzing mechanical behavior of steel, which is more relevant, to correlate it with steel fracture and associated hot ductility, instead of performing separate tensile tests. Since failure occurred in the center of the specimen which was maintained at isothermal test temperature at all times during the hot ductility test, it is safe to use this tensile data. Such analysis helped in directly correlating the variation in hot ductility observed with changes in high temperature mechanical properties of steel. Continuous cooling phase transformation modeling was done using JMatPro for all steels.

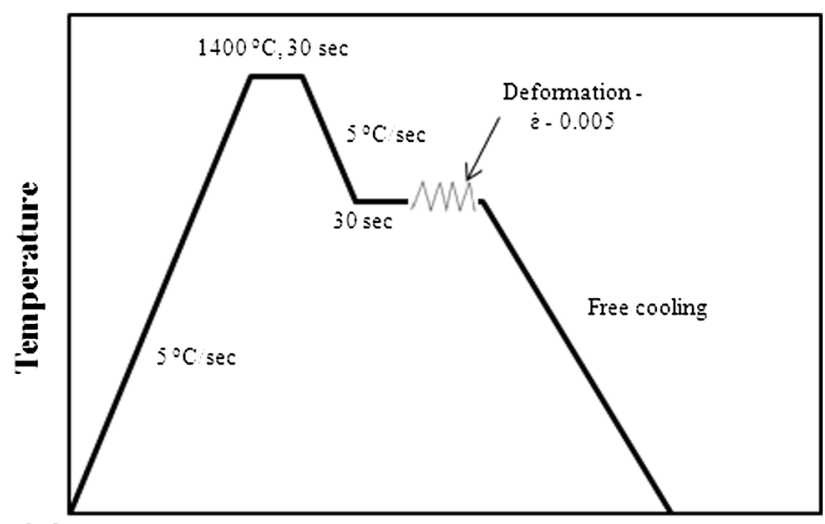

(a)

Time

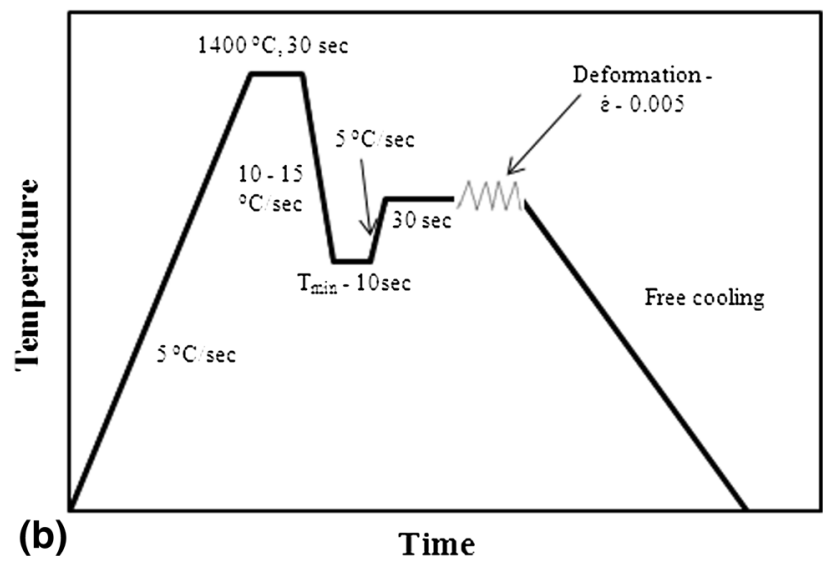

Fig. 1 Schematic of thermal cycles applied to different steel specimen; (a) Steel 1, (b) Steel 2

Table 1 Chemical composition of steel (wt.\%)

\begin{tabular}{llllllllllll}
\hline Steel no. & $\mathbf{C}$ & Mn & Si & P & S & N & Nb & Al & Ca & Mn/S & Modified Mn/S \\
\hline 1 & 0.18 & 0.87 & 0.1 & 0.01 & 0.005 & 0.006 & $\ldots$ & 0.03 & 0.0025 & 174 & 464 \\
2 & 0.18 & 1.3 & 0.17 & 0.01 & 0.005 & 0.0065 & $\ldots$ & 0.025 & 0.0025 & 260 & 693 \\
3 & 0.06 & 0.82 & 0.14 & 0.01 & 0.005 & 0.0115 & 0.015 & 0.025 & 0.0025 & 164 & 437 \\
\hline
\end{tabular}




\section{Results}

\subsection{Hot Ductility}

Reduction of area ( $\mathrm{R}$ of $\mathrm{A}$ ) is plotted as a function of temperature as shown in Fig. 2. Under the experimental testing conditions, to ensure freedom from cracking during commercial casting, minimum $40 \% \mathrm{R}$ of $\mathrm{A}$ is required (Ref 2). In case of Steel 1 , having tested using conventional test without undercooling step, loss of ductility is observed at $800{ }^{\circ} \mathrm{C}$. Hot ductility decreases from about $85 \%$ at $850{ }^{\circ} \mathrm{C}$ to $67 \%$ at $800{ }^{\circ} \mathrm{C}$ and continues until $700{ }^{\circ} \mathrm{C}$. Though ductility always remains over $40 \%$ critical limit, second trough occurs between 900 and $1100{ }^{\circ} \mathrm{C}$, and finally above $1300{ }^{\circ} \mathrm{C}$. Different zones of hot ductility drops observed in present steel are as identified in Fig. 2(c). Steel 2 shows loss of ductility below $900{ }^{\circ} \mathrm{C}$ and continues until $800{ }^{\circ} \mathrm{C}$ in zone I. Zone II extends from 1050 to $1150{ }^{\circ} \mathrm{C}$, while zone III is observed above $1350{ }^{\circ} \mathrm{C}$. Undercooling introduced in thermal cycle causes deepening and widening of ductility trough in Steel 2. Trough deepens by almost $35 \% \mathrm{R}$ of $\mathrm{A}$ and widens by $150{ }^{\circ} \mathrm{C}$ toward higher temperature in zone I. However, width of zone II is reduced and zone III shifts by $50{ }^{\circ} \mathrm{C}$ to higher temperature.

The presence of $\mathrm{S}$ in steel causes segregation of fine sulfides along the grain boundaries and weakens them, thereby reducing the hot ductility of steel. However, higher $\mathrm{Mn} / \mathrm{S}$ ratio or $\mathrm{Ca}$ treatment of steel is found to improve the hot ductility (Ref 2). $\mathrm{Ca}$ is added to avoid/modify $\mathrm{MnS}$ particles in steel and assuming that all $\mathrm{Ca}$ effectively binds $\mathrm{S}$, the resulting modified $\mathrm{Mn} / \mathrm{S}$ ratios are as reported in Table 1 along with $\mathrm{Mn} / \mathrm{S}$ ratio. In the present study, in spite of better $\mathrm{Mn} / \mathrm{S}$ ratio, hot ductility is inferior in Steel 2. Steel 3 shows the presence of only zone I where loss of ductility is observed at $900{ }^{\circ} \mathrm{C}$ and ductility recovery starts below $800{ }^{\circ} \mathrm{C}$.

\subsection{Fractography}

3.2.1 Steel 1. Fractured surface of samples of Steel 1 is as shown in Fig. 3. Solution treatment generated a very coarse grain structure as observed at $700{ }^{\circ} \mathrm{C}$, thus ensuring cracking tendencies similar to that present in cast structure. At $700{ }^{\circ} \mathrm{C}$, surface shows intergranular nature of failure, marked with sliding steps along the grain boundaries as well as large amount of dimples and voids. The presence of sliding steps along the grain boundaries indicates that small amount of deformation happened before tearing of deformed grains. Dimples on grain boundary surfaces suggest occurrence of ferrite nucleation along the austenite grain boundary and deformation concentrated in these ferrite bands leading to decohesion with the matrix and subsequent failure. Intergranular failure is observed at $800{ }^{\circ} \mathrm{C}$ also, but surface is distinct from that observed at $700{ }^{\circ} \mathrm{C}$. Fractured surface shows small voids similar to those observed at $700{ }^{\circ} \mathrm{C}$ along with extremely large voids of the order of $100 \mu \mathrm{m}$ or more. Smaller voids and craters appear together with sliding steps. Fractured surface at $800{ }^{\circ} \mathrm{C}$ is devoid of flat facets and dimples, indicating growth dominant fracture at $800{ }^{\circ} \mathrm{C}$ in contrast to nucleation dominant fracture at $700{ }^{\circ} \mathrm{C}$.

Samples fractured at $850{ }^{\circ} \mathrm{C}$ shows intergranular failure, with the presence of large voids having very thin edges in addition to considerable proportion of microvoids in the size range of 5-10 $\mu \mathrm{m}$. The absence of sliding steps near void edges indicates continuous material flow and eventual ductile neck-
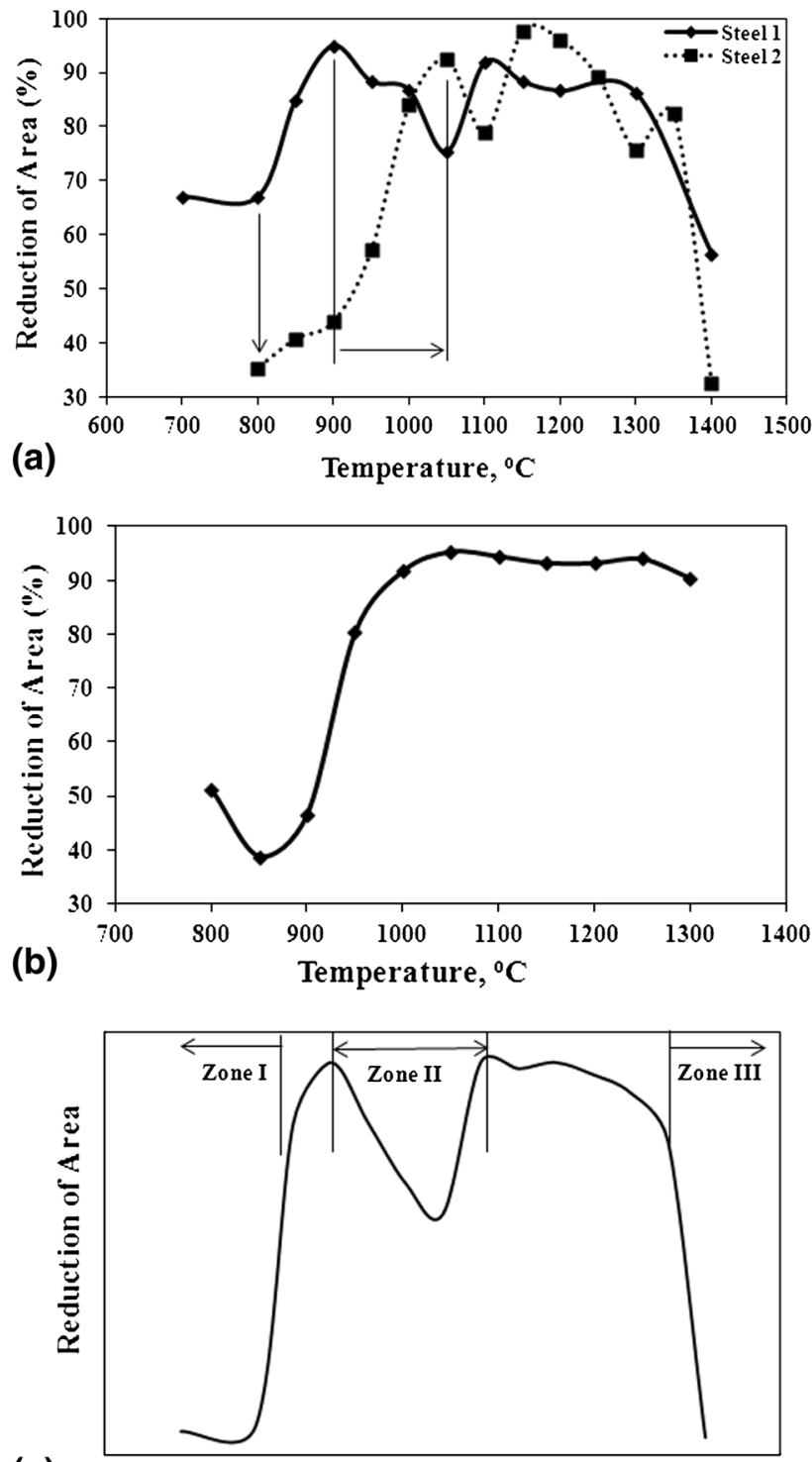

(c)

Temperature

Fig. 2 Reduction of area as a function of temperature for; (a) Steel 1 and 2, (b) Steel 3, and (c) schematic showing different zones of hot ductility drops

ing. $\mathrm{Mn}$ and $\mathrm{Al}$ containing spherical inclusion particles are also found at grain boundary triple junctions. SEM image of samples fractured at both 1050 and $1200{ }^{\circ} \mathrm{C}$ indicates transgranular nature of failure, with the presence of completely deformed grain structure.

3.2.2 Steel 2. Figure 4 shows fractured surfaces of Steel 2. Fractured surface at $800{ }^{\circ} \mathrm{C}$ shows sufficiently large area having flat facets of the order of millimeter size, considered to be the cause of worst ductility. Similar flat facets are exhibited by smaller grains in the range of $100-300 \mu \mathrm{m}$ indicating intergranular failure devoid of any deformation. At $850{ }^{\circ} \mathrm{C}$, fracture is intergranular in nature with grains in the range of $100-200 \mu \mathrm{m}$, showing flat facets as well as large amount of sliding marks indicating grain boundary sliding. Grain boundaries display the presence of small amount of shallow craters with inclusion particles embedded at few locations. Fracture at $900{ }^{\circ} \mathrm{C}$ exhibit mixed nature of failure surfaces. Failed surface consists of smooth facets, microvoids, localized necking at 

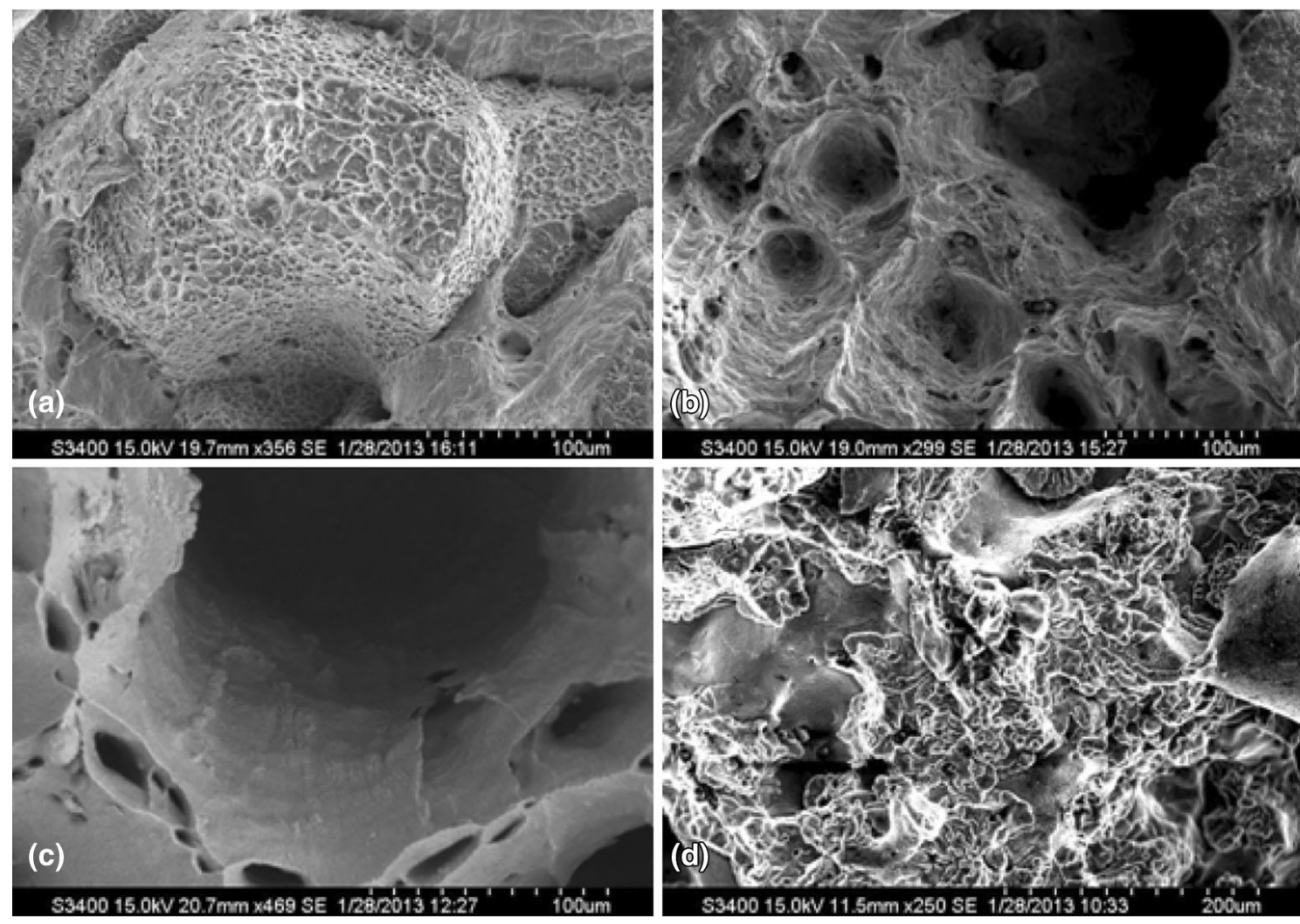

Fig. 3 SEM images of fractured surfaces of Steel 1 after hot tensile test at; (a) $700{ }^{\circ} \mathrm{C}$, (b) $800{ }^{\circ} \mathrm{C}$, (c) $850{ }^{\circ} \mathrm{C}$, and (d) $1200{ }^{\circ} \mathrm{C}$

grain boundaries indicating substantial deformation before failure. Intergranular fracture at $950{ }^{\circ} \mathrm{C}$ is observed with substantial decrease in flat facets and considerable amount of elongated grains owing to large necking before failure. Transgranular failure is observed at $1000{ }^{\circ} \mathrm{C}$ with grain sizes in the range of 50-150 $\mu \mathrm{m}$ and hence the high ductility. Similar failure characteristics are observed at 1050 and $1200{ }^{\circ} \mathrm{C}$, with highly deformed grains.

At $1300{ }^{\circ} \mathrm{C}$, fractured surfaces are smooth with slight sliding marks along with spherical-embedded inclusion particles largely containing $\mathrm{Mn}, \mathrm{Si}$, and occasionally $\mathrm{Al}$. The grain boundaries and fracture surfaces are smoother and devoid of any deformation at $1400{ }^{\circ} \mathrm{C}$ with significant number of inclusion particles present at the grain boundaries. The inclusion particles or area adjacent to the grain boundaries were found to be rich with oxides and/or sulfides, mainly containing $\mathrm{Mn}$ and Si. Wedge-shaped cracks were found at triple-point junctions. Fracture at high temperature indicated failure due to grain boundary sliding at $\gamma-\gamma$ interface without any deformation. The presence of inclusion particles along the grain boundary indicates particle-stimulated grain boundary sliding and hence lower ductility.

3.2.3 Steel 3. Tensile fracture surfaces of Steel 3 are shown in Fig. 5. Intergranular fracture characteristics are observed at $800{ }^{\circ} \mathrm{C}$, in addition to the significant amount of large craters indicating formation of ferrite nuclei, void generation at $\alpha-\gamma$ interface and subsequent void coalescence leading to failure. Features observed at $850{ }^{\circ} \mathrm{C}$ are almost similar to those observed at $800{ }^{\circ} \mathrm{C}$ including the presence of sliding marks, except craters are comparatively shallow at higher temperature. This indicates lesser amount of ferrite presence at $850{ }^{\circ} \mathrm{C}$. At $900{ }^{\circ} \mathrm{C}$, failure along the grain boundary is devoid of any craters. The fracture surface shows flat facets, grain sliding marks, and microvoids formed due to dislodgement of embedded particles. Elongated grains and necking at grain boundaries indicate large amount of deformation at $950{ }^{\circ} \mathrm{C}$ before failure. Microvoids are also observed in the size range of $5-20 \mu \mathrm{m}$ indicative of prior presence of inclusion particles dislodged during deformation. However, at $1150{ }^{\circ} \mathrm{C}$ even though sample showed very good ductility, fractured surface exhibited mixed mode of failure, i.e., with intergranular/transgranular nature. Similarly, at $1300{ }^{\circ} \mathrm{C}$ intergranular failure is observed with high ductility. Wedge cracks at triple junctions are present with sliding marks along the grain boundaries indicating grain boundary sliding.

In all the steels, failure is intergranular in nature corresponding to inferior hot ductility at low temperatures in zone I. With increase in temperature, failure mode transforms to a mixed mode marked with elongated grains and finally to transgranular nature at intermediate temperatures in austenitic range. At high temperatures, fractures are intergranular in nature, distinct from those observed at low temperature, owing to the presence of smooth surfaces and wedge-type cracks at triple junctions.

\subsection{Mechanical Properties}

True stress-strain plot for Steel 2 is shown in Fig. 6. True stress-true strain plots for investigated steels show characteristics hump and/or multiple peaks indicating start of recovery/ recrystallization in steel at $850{ }^{\circ} \mathrm{C}$ for Steel 1 , and $950{ }^{\circ} \mathrm{C}$ for Steel 2 and 3. Yield stress (YS) of steels is determined using $0.2 \%$ offset method due to continuous yielding of steel at high temperature whereas peak stress corresponds to the max. true stress. Mishra et al. (Ref 14) found that the Swift equation provides better correlation coefficient for strain hardening 

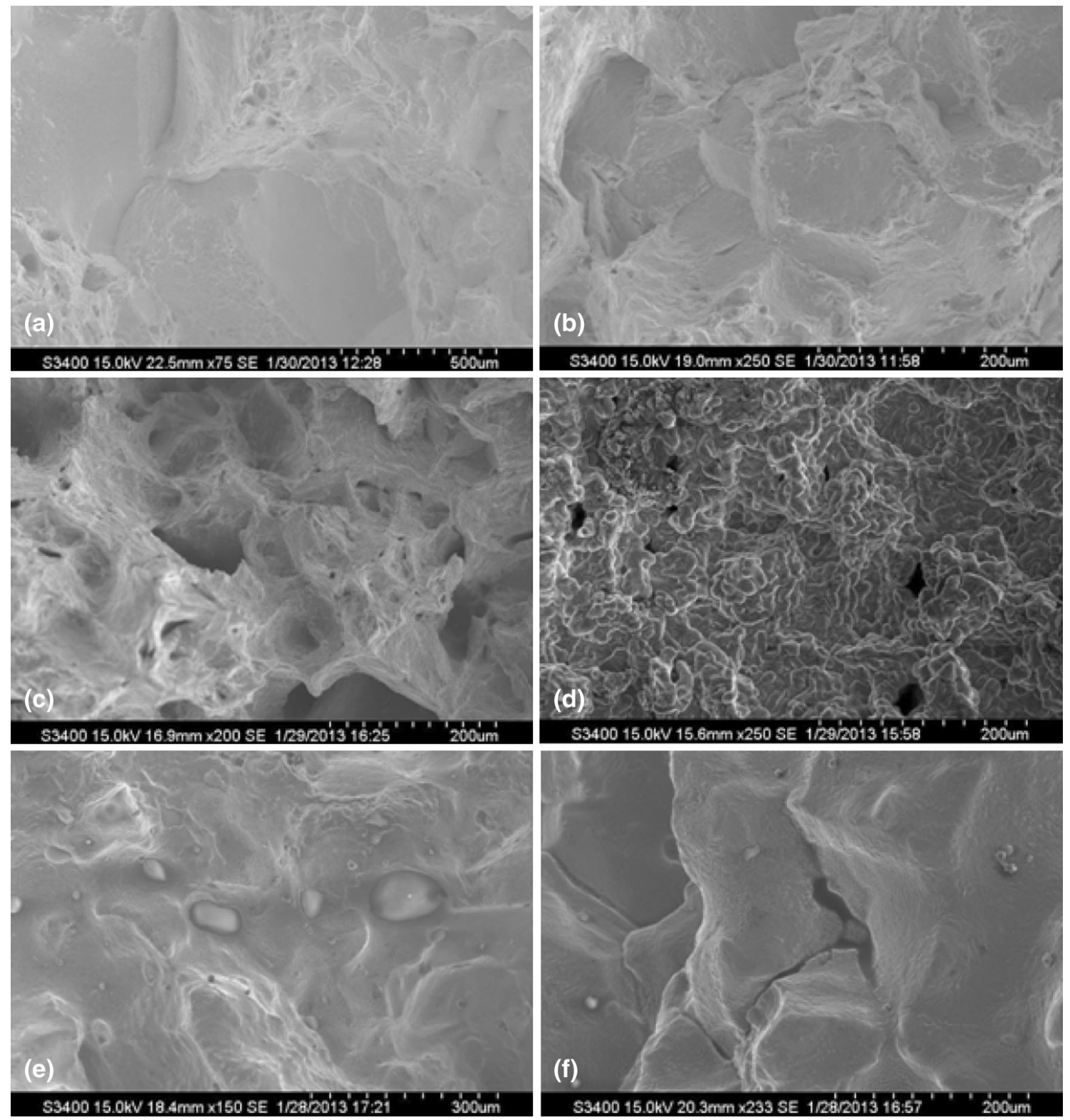

Fig. 4 SEM images of fractured surfaces of Steel 2 after hot tensile test at; (a) $800{ }^{\circ} \mathrm{C}$, (b) $850{ }^{\circ} \mathrm{C}$, (c) $950{ }^{\circ} \mathrm{C}$, (d) $1000{ }^{\circ} \mathrm{C}$, (e) $1300{ }^{\circ} \mathrm{C}$, and (f) $1400{ }^{\circ} \mathrm{C}$

behavior of high strength steels at temperatures above $500{ }^{\circ} \mathrm{C}$, while Hollomon and Ludwik expressions become equivalent. Hence for simplicity Hollomon equation;

$\sigma=k \varepsilon^{n}$

was used to calculate the strain hardening coefficient $(n)$, strength coefficient $(k)$, and work hardening rate $(W H R)$ at different test temperatures. $n$ is the slope of the log-log plot of true stress and true strain up to maximum load, $k$ is the true stress at $\varepsilon=1.0$ and $W H R$ is given as $(\operatorname{Ref} 15)$ :

$\frac{d \sigma}{d \varepsilon}=n \frac{\sigma}{\varepsilon}$.

3.3.1 Steel 1. Figure 7 shows different tensile properties of Steel 1 plotted against test temperature. Figure 7(a) shows variation of $Y S$, peak stress and yield ratio (Ratio of $Y S /$ peak stress) with temperature. As expected $Y S$ and peak stress decreases with increasing temperature, however with a slope change at $1050{ }^{\circ} \mathrm{C}$ and yield ratio increases with temperature above $800{ }^{\circ} \mathrm{C}$ until $1150{ }^{\circ} \mathrm{C}$. Peak strain and $n$ initially increases between 700 and $800{ }^{\circ} \mathrm{C}$, and decreases with temperature above $800{ }^{\circ} \mathrm{C}$ as shown in Fig. 7(b). The decrease in $n$ is gradual while peak strain shows an inflection at $1050{ }^{\circ} \mathrm{C}$. Figure 7(c) shows that $W H R$ and $k$ decreases with temperature, with slope of change decreasing above $1050{ }^{\circ} \mathrm{C}$.

3.3.2 Steel 2. Tensile properties of Steel 2 are plotted with test temperature in Fig. 8. As shown in Fig. 8(a) decrease in $Y S$ and peak stress is observed with increase in temperature, but unlike Steel 1 change of slope is observed at 850 and $1100{ }^{\circ} \mathrm{C}$. Yield ratio initially decreases until $850{ }^{\circ} \mathrm{C}$, but later increases with increasing temperature. Peak strain and $n$ both increases until $850{ }^{\circ} \mathrm{C}$, and decreases further with increasing temperature, in Fig. 8(b). However, unlike $n$ peak strain starts increasing 

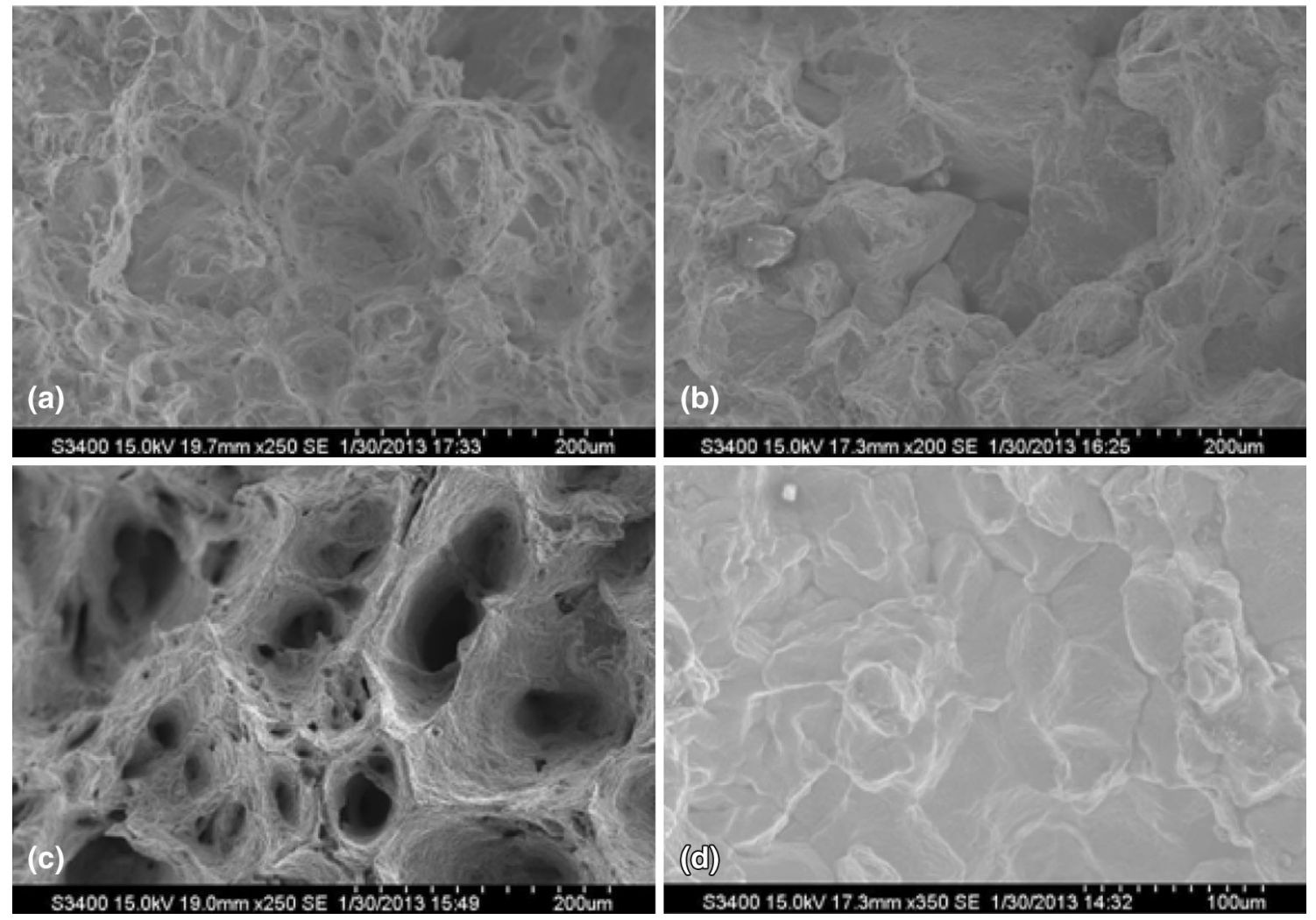

Fig. 5 SEM images of fractured surfaces of Steel 3 after hot tensile test at; (a) $800{ }^{\circ} \mathrm{C}$, (b) $900{ }^{\circ} \mathrm{C}$, (c) $950{ }^{\circ} \mathrm{C}$, and (d) $1300{ }^{\circ} \mathrm{C}$

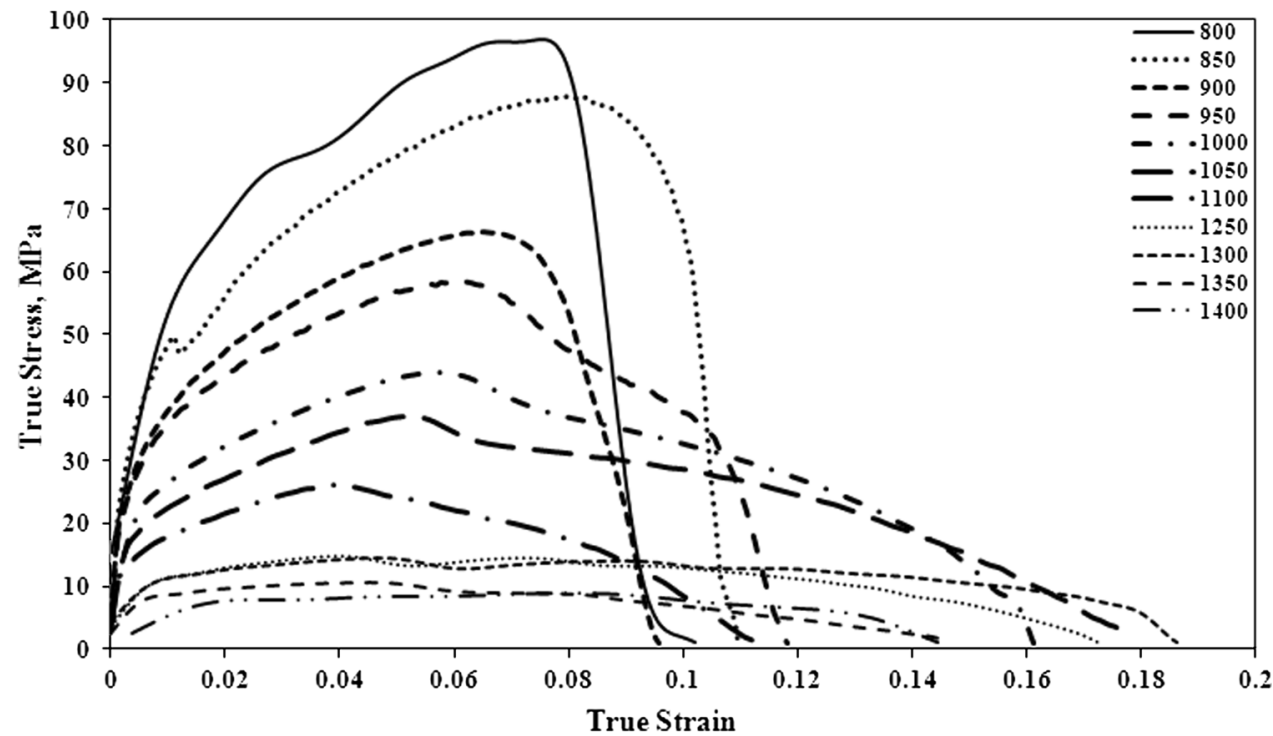

Fig. 6 True stress-true strain plot for Steel 2

above $1250{ }^{\circ} \mathrm{C}$. Figure 8 (c) shows almost constant $k$ until $850{ }^{\circ} \mathrm{C}$ before decreasing with temperature, whereas $W H R$ increases until $850{ }^{\circ} \mathrm{C}$ and then decreases with the increase in temperature. Both $W H R$ and $k$ show slope change at $1100{ }^{\circ} \mathrm{C}$.

3.3.3 Steel 3. Both $Y S$ and peak stress for Steel 3 decrease with the increase in temperature as shown in Fig. 9(a). Similar to Steel 2, slope of change varies with temperature. Peak stress decreases slowly between 800 and
$900{ }^{\circ} \mathrm{C}$, then rapid decrease is observed until $1100{ }^{\circ} \mathrm{C}$, and finally a slow decrease at high temperature. Conversely, $Y S$ decreases rapidly between 800 and $900{ }^{\circ} \mathrm{C}$, compared to slower decrease at higher temperature with slope change observed at $1100{ }^{\circ} \mathrm{C}$. Accordingly yield ratio decreases until $900{ }^{\circ} \mathrm{C}$ before increasing again.

Figure 9(b) shows increase in peak strain until $900{ }^{\circ} \mathrm{C}$ before decreasing at higher temperature with a change in slope 

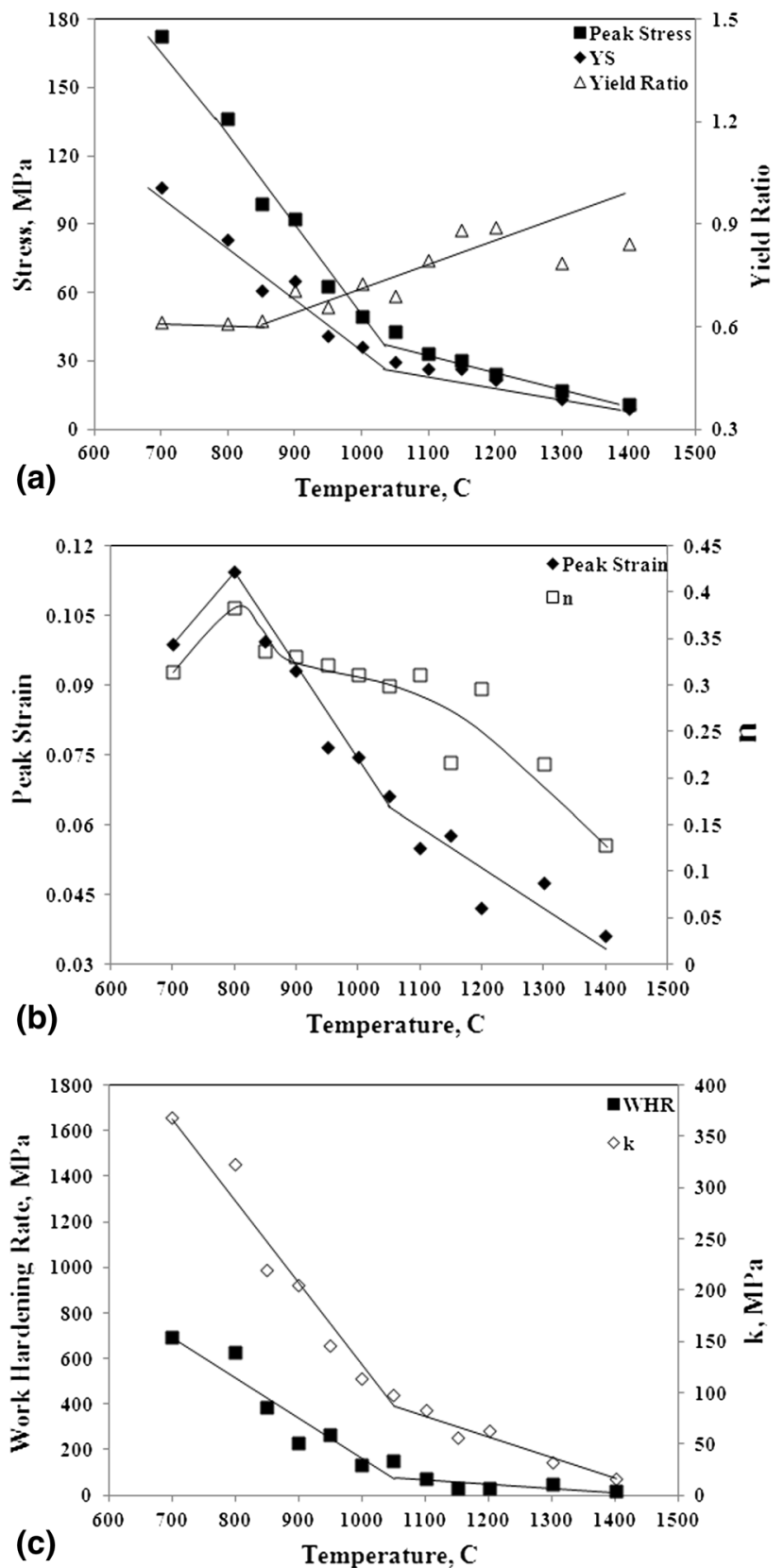

Fig. 7 Tensile properties vs. temperature of Steel 1, (a) YS, peak stress, and yield ratio, (b) peak strain and $n$, and (c) work hardening rate and $k$

at $1100{ }^{\circ} \mathrm{C} . n$ shows similar pattern except decrease above $900{ }^{\circ} \mathrm{C}$ is more gradual. As expected from the values of peak stress and $n, W H R$ increases until $900{ }^{\circ} \mathrm{C}$ and decreases above $900{ }^{\circ} \mathrm{C}$ with a slope change at $1100{ }^{\circ} \mathrm{C}$ as shown in Fig. 9(c). $k$ also shows similar pattern.

Even though Steel 2 contains higher Mn, it shows lower $Y S$ and peak stress than Steel 1. At temperatures above 1050$1100{ }^{\circ} \mathrm{C}$, values of $W H R$ and $k$ are similar in both Steel 1 and 2, while Steel 3 shows better WHR in mid-to-high temperature range than Steel 2. In spite of better $n$ and peak stress observed in Steel 1, WHR is considerably lower compared to other steels. Steel 2 shows rapid drop in peak stress, WHR and $k$ with temperature than Steel 3.
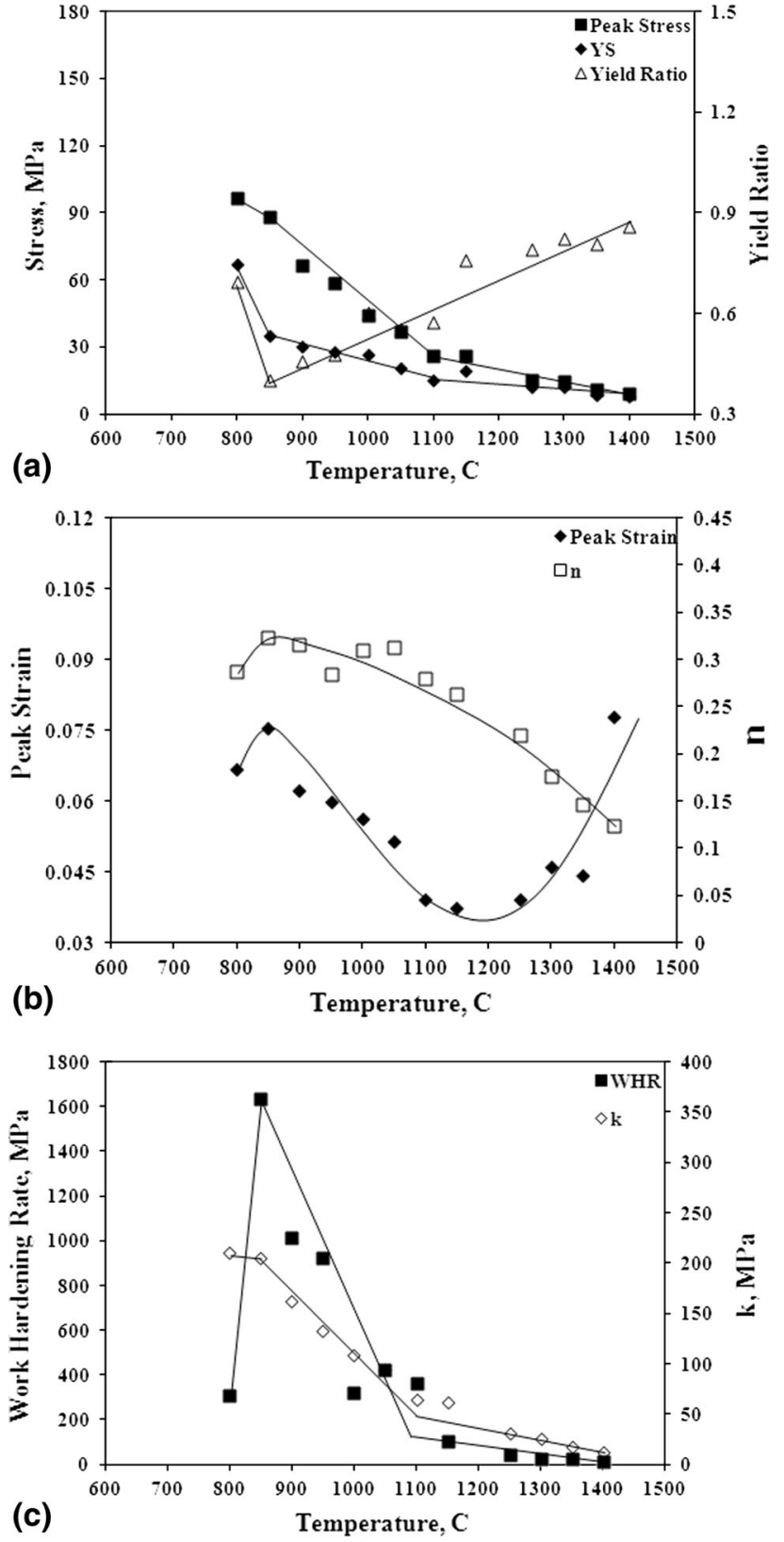

Fig. 8 Tensile properties vs. temperature of Steel 2, (a) YS, peak stress, and yield ratio, (b) peak strain and $n$, and (c) work hardening rate and $k$

\subsection{Modeling}

Continuous cooling transformation was modeled using JMatPro - the materials property simulation package (Ref 16). At high temperature during solidification, with increase in ferrite content liquid phase becomes saturated with $\mathrm{C}, \mathrm{Mn}, \mathrm{S}, \mathrm{P}$, and $\mathrm{Si}$ in the inter-dendritic region. Inferior ductility observed in zone III is an attribute of this impurity-saturated steel having lower melting point than bulk steel.

Segregated $\mathrm{Mn}$ and $\mathrm{S}$ combine and precipitate along the austenite grain boundaries below solution temperature. Even though closed packed hexagonal structure poses difficulty for AIN to precipitate in austenite, MnS particles formed prior to 

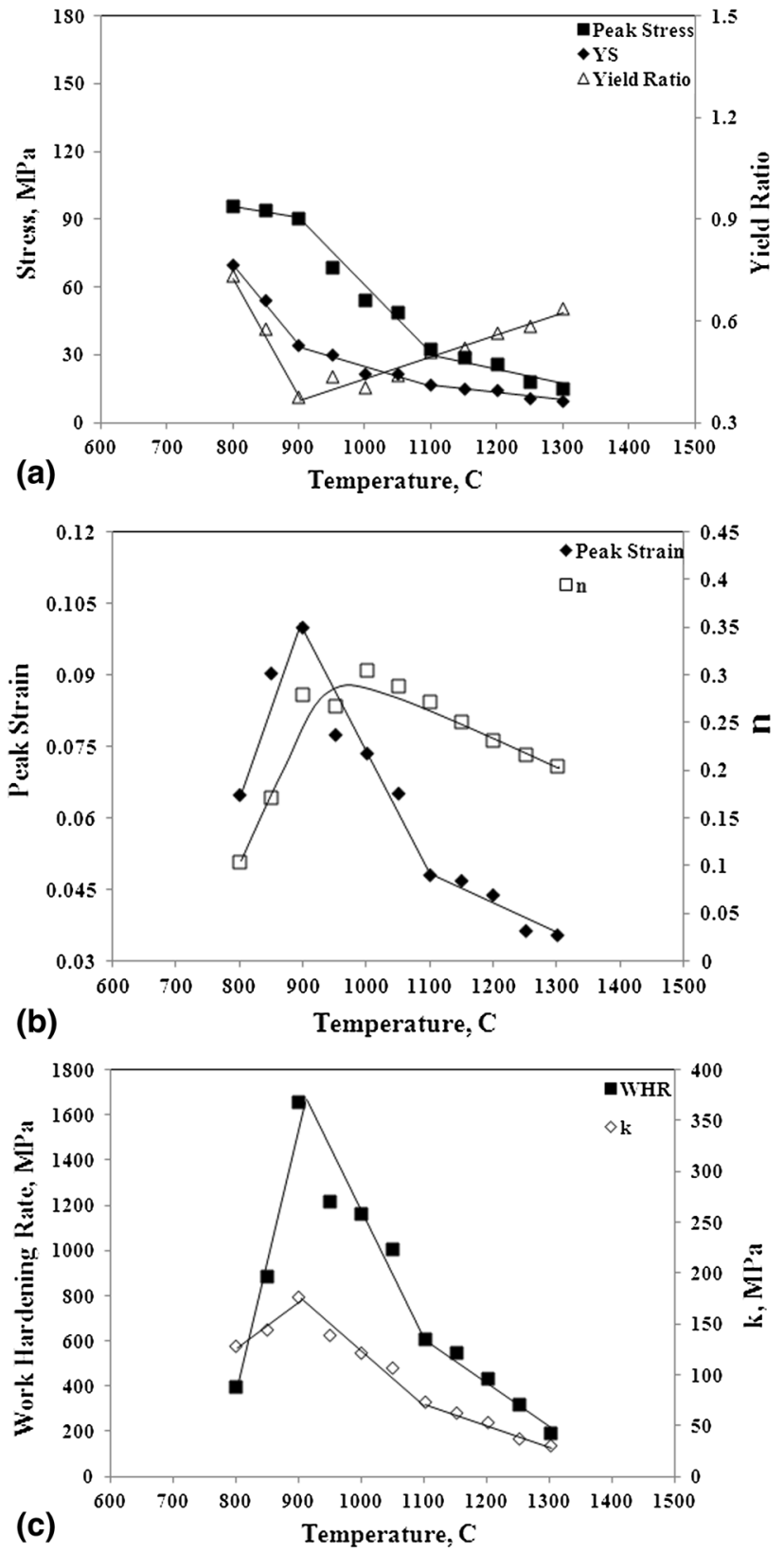

Fig. 9 Tensile properties vs. temperature of Steel 3, (a) YS, peak stress, and yield ratio, (b) peak strain and $n$, and (c) work hardening rate and $k$
AlN act as nucleation sites for AlN precipitation (Ref 17, 18). In the present investigation also Al was found associated with $\mathrm{Mn}$ and Si containing particles along the grain boundary as shown in Fig. 10. Figure 11 shows on-cooling phase transformation modeling results for Steel 1. On-cooling phase transformation simulation predicts almost complete $\mathrm{MnS}$ precipitation for all the three steels by the time temperature reaches $1150{ }^{\circ} \mathrm{C}$, whereas AIN precipitation shows near completion at about $900{ }^{\circ} \mathrm{C}$ for Steel 3 and $950{ }^{\circ} \mathrm{C}$ for Steel 1 and 2. $\mathrm{Nb}(\mathrm{C}, \mathrm{N})$ precipitation for Steel 3 is predicted below $1080{ }^{\circ} \mathrm{C}$.

\section{Discussion}

Hot ductility results indicate deterioration of ductility in steel when given undercooling and reheating treatment, the condition to which continuously cast steel products are exposed in the secondary cooling zone. Even with high $\mathrm{Mn} / \mathrm{S}$ ratio in Steel 2, ductility recovery is delayed at high temperature end of trough. Both Steel 1 and 2 exhibit drop in ductility at midtemperature range of $900-1100$ and $1050-1150{ }^{\circ} \mathrm{C}$, respectively, and finally at high temperature. However, $\mathrm{Nb}$-microalloyed steel shows ductility drop only at lower temperature in the vicinity of ferrite transformation range. Suzuki et al. (Ref 6) found that zone I embrittlement is caused by intergranular precipitation, pro-eutectoid film formation along the austenite grain boundaries, and grain boundary sliding. Intergranular precipitation of sulfides and oxides along the grain boundaries is thought to cause zone II embrittlement, while liquid phase embrittlement is the reason for cracking in zone III.

In the present case, steel with zone I embrittlement shows the presence of flat facets, dimples, and shallow craters indicating ferrite nucleation, which leads to intergranular failure due to void formation at ferrite followed by void coalescence and failure. The presence of sliding steps indicates grain boundary sliding before tearing of deformed grains occur. The start of ferrite nucleation is indicated by change in mechanical behavior of steel. Yield ratio decreases with decreasing temperature, accommodating more deformation before fracture, but starts increasing again due to nucleation of ferrite in the structure. This effect is more prominent in Steel 2 and 3 which can be ascribed to the undercooling and reheating thermal treatment. As expected peak strain and $n$, on the other hand, increases with decreasing temperature but starts dropping owing to ferrite transformation. $Y S$, peak stress, $W H R$
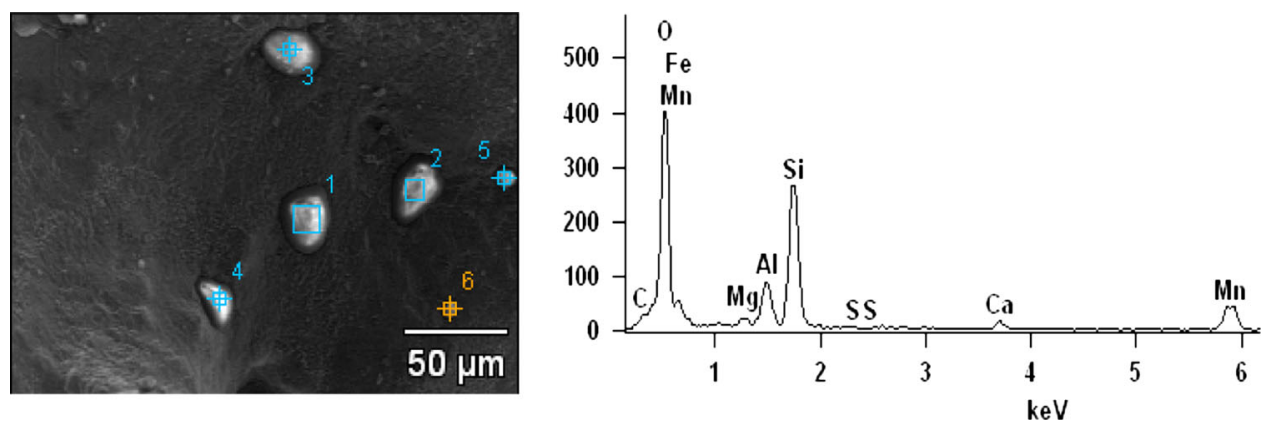

Fig. 10 EDX analysis of particle at grain boundary indicating the presence of majorly $\mathrm{Mn}, \mathrm{Si}, \mathrm{Fe}$, and $\mathrm{Al}$ 
and $k$ suggests start of ferrite transformation in Steel 2 and 3, but not in Steel 1, an attribute of different thermal histories employed. Thus, ferrite transformation is observed at and below 800, 850, and $900{ }^{\circ} \mathrm{C}$ for Steel 1, Steel 2, and Steel 3, respectively.

Using relations from literature, $A r_{3}$ for Steel 1 and $A c_{3}$ temperatures for Steel 2 and 3, are calculated as shown in Table 2 (Ref 19-26). For Steel 1, relation from Shiga et al. and Kariya et al. gives nearest results while Kasatkin's relation gives consistent results to those observed in present study for both Steel 2 and 3. Mintz et al. recently published a relation to predict un-deformed $\mathrm{Ar}_{3}\left(\mathrm{Ar}_{3 \mathrm{U}}\right)$, which includes cooling rate in correlation (Ref 27). However, cooling rates used in the present study for Steel 1 are much higher than those applicable in above relation. Though $A c_{3}$ temperatures lie slightly above $A r_{3}$ temperatures, Steel 2 contains higher Mn than Steel 1 which has a decreasing effect on transformation temperature. Considering that, appreciable differences between ferrite transformation temperatures of Steel 1 and 2 can be justified on account of enhancement of ferrite transformation in Steel 2 owing to undercooling and reheating cycle.

Appearance of zone II in Steel 1 and 2 is due to two parameters; namely inferior work hardening capacity of austenite and absence of recrystallization. WHRs of Steel 1 and 2 in zone II are inferior to Steel 3 which shows the absence of zone II embrittlement. Decrease in slope of change observed in $Y S$, peak stress, peak strain, $W H R$, and $k$ plots, above $1050{ }^{\circ} \mathrm{C}$ in Steel 1 and $1100{ }^{\circ} \mathrm{C}$ in Steel 2 and 3, is due to the onset of recrystallization as witnessed by multiple peaks in true stress-true strain curve. Hence, above $1050{ }^{\circ} \mathrm{C}$ in Steel 1 and $1100{ }^{\circ} \mathrm{C}$ in Steel 2, ductility recovers on account of recrystallization until finally dropping again in zone III. Alloying elements enhancing work hardening rates in austenitic range can be promoted to discourage steel embrittlement in zone II.

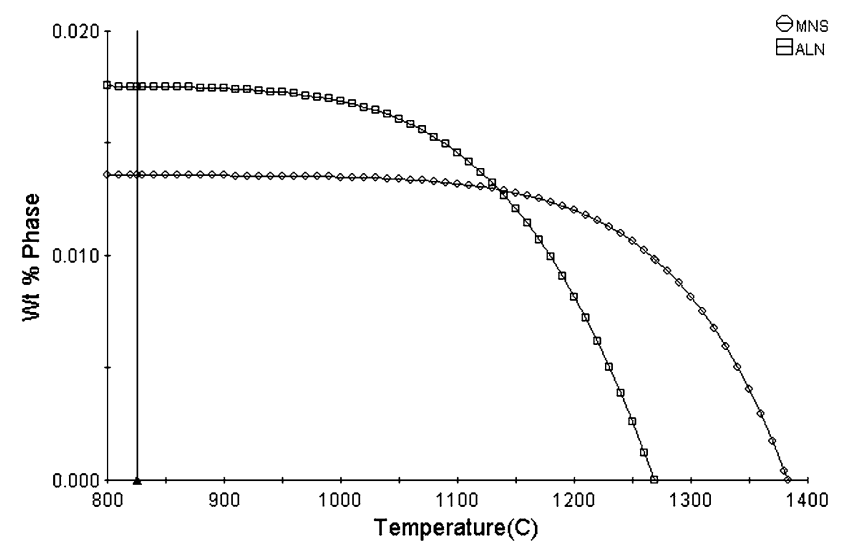

Fig. 11 Phase fraction modeling for Steel 1
Phase transformation modeling results show near completion $\mathrm{MnS}$ precipitation at $1150{ }^{\circ} \mathrm{C}$ during cooling in all the three steels, whereas disappearance of recrystallization is observed at slightly lower temperatures. Hence, recrystallization is thought to be affected only after sufficient build-up of AlN particles along with MnS particles in the structure. Suzuki et al. (Ref 7) have termed $\mathrm{Al}$ as a debatable element in terms of its effect on hot ductility of steel. However, Al in its nitride form seems to have a retarding effect on recrystallization and thus deleteriously affects the hot ductility of steel as observed in the present study. Therefore, zone II embrittlement in Steel 1 and 2 is caused by both inferior work hardening capacity of austenite as well as suppression of recrystallization due to the presence of AlN and MnS particles along the austenite grain boundaries.

Zone III is a high temperature region nearing melting point where the presence of low melting phase in interdendritic region causes embrittlement along the grain boundary and hence lower strength and ductility is observed.

\section{Conclusion}

Hot ductility study of C-Mn and C-Mn-Nb steel has been performed with/without thermal oscillation and change in mechanical behavior with test temperature has been investigated. The conclusions drawn are as follows:

1. Ductility troughs are observed in three distinct zones in C-Mn steels, whereas C-Mn-Nb steel shows loss of ductility only at lower temperature.

2. In presence of undercooling and reheating cycle analogues to secondary cooling in continuous casting, hot ductility of steel deteriorates as compared to when thermal oscillation is absent. Thermal oscillation is found to enhance the ferrite transformation in C-Mn and C-Mn-Nb steels.

3. In presence of thermal oscillation, ferrite nucleation causes increase in yield ratio and accordingly peak strain and $n$ decreases, thus limiting the elongation before failure initiation; whereas $W H R$ and $k$ demonstrate a decline with the start of ferrite transformation.

4. Embrittlement in zone I is attributed to the start of ferrite transformation, with subsequent void nucleation at ferrite band and void coalescence leading to intergranular failure. Ductility drop in zone II through austenitic range is due to very low work hardening rates with the absence of any ductility recovery by way of recrystallization. Hot ductility of austenite recovers only after appearance of recrystallization. Zone III embrittlement is caused by the

Table $2 \mathrm{Ar}_{3}$ and $A c_{3}$ temperatures calculated using relations from literature (Ref 19-26)

\begin{tabular}{|c|c|c|c|c|}
\hline \multirow[b]{2}{*}{ References } & \multirow{2}{*}{$\begin{array}{c}\text { Calculated } \mathrm{Ar}_{3} \\
\text { temperature } \\
\text { Steel } 1\end{array}$} & \multirow[b]{2}{*}{ References } & \multicolumn{2}{|c|}{$\begin{array}{c}\text { Calculated } A c_{3} \\
\text { temperature }\end{array}$} \\
\hline & & & Steel 2 & Steel 3 \\
\hline Shiga et al. (Ref 19) & 797 & Hougardy (Ref 23) & 845 & 880 \\
\hline Choquet et al. (Ref 20$)$ & 759 & Kasatkin et al. (Ref 24) & 838 & 887 \\
\hline Pickering (Ref 21$)$ & 855 & Park et al. (Ref 25$)$ & 870 & 924 \\
\hline Kariya et al. (Ref 22) & 802 & Trzaska et al. (Ref 26) & 826 & 873 \\
\hline
\end{tabular}


presence of impurity enriched low melting phase along the austenite grain boundary resulting in intergranular fracture.

5. In spite of recovery, recrystallization is inhibited in austenitic range after sufficient build-up of AlN particles along with $\mathrm{MnS}$ precipitates next to the austenitic grain boundary.

6. Alloying elements enhancing work hardening rates in austenitic range can be promoted to discourage steel embrittlement in zone II.

\section{References}

1. W.T. Lankford, Jr., Some Considerations of Strength and Ductility in the Continuous-Casting Process, Metall. Trans., 1972, 3, p 1331-1357

2. B. Mintz, The Influence of Composition on the Hot Ductility of Steels and to the Problem of Transverse Cracking, ISIJ Int., 1999, 39(9), p 833-855

3. P. Deprez, J.P. Bricout, and J. Oudin, A New Tensile Test on In Situ Solidified Notched Specimens: Hot Ductility Analysis of Continuous Casting Steels, J. Mater. Process. Technol., 1992, 32(1-2), p 325-334

4. T. Revaux, P. Deprez, J.P. Bricout, and J. Oudin, In Situ Solidified Hot Tensile Test and Hot Ductility of Some Plain Carbon Steels and Microalloyed Steels, ISIJ Int., 1994, 34(6), p 528-535

5. G.A. Wilber, R. Batra, W.F. Savage, and W.J. Childs, The Effects of Thermal History and Composition on the Hot Ductility of Low Carbon Steels, Metall. Trans. A, 1975, 6A, p 1727-1735

6. H.G. Suzuki, S. Nishimura, and S. Yamaguchi, Characteristics of Hot Ductility in Steels Subjected to the Melting and Solidification, Trans. ISIJ, 1982, 22, p 48-56

7. H.G. Suzuki, S. Nishimura, J. Imamura, and Y. Nakamura, Embrittlement of Steels Occurring in the Temperature Range from 1000 to $600{ }^{\circ} \mathrm{C}$, Trans. ISIJ, 1984, 24, p 169-177

8. J. Calvo, A. Rezaeian, J.M. Cabrera, and S. Yue, Effect of the Thermal Cycle on the Hot Ductility and Fracture Mechanisms of a C-Mn Steel, Anales de Mecanica De La Fractura, 2005, 22, p 184-189

9. C. Ouchi and K. Matsumoto, Hot Ductility in Nb-Bearing HighStrength Low-Alloy Steels, Transactions ISIJ, 1982, 22, p 181-189

10. K. Cho, D. Mun, M. Kang, J. Lee, J. Park, and Y. Koo, Effect of Thermal Cycle and Nitrogen Content on the Hot Ductility of BoronContaining Steel, ISIJ Int., 2010, 50(6), p 839-846
11. B. Mintz, J.M. Stewart, and D.N. Crowther, The Influence of Cyclic Temperature Oscillations on Precipitation and Hot Ductility of a C-MnNb-Al Steel, Trans. ISIJ, 1987, 27, p 959-964

12. C. Spradbery and B. Mintz, Influence of Undercooling Thermal Cycle on Hot Ductility of C-Mn-Al-Ti and C-Mn-Al-Nb-Ti Steels, Ironmak. Steelmak., 2005, 32(4), p 319-324

13. K.M. Banks, A. Tuling, and B. Mintz, Influence of Thermal History on Hot Ductility of Steel and Its Relationship to the Problem of Cracking in Continuous Casting, Mat. Sci. Technol., 2012, 28(5), p 536-542

14. N.S. Mishra, S. Mishra, and V. Ramaswamy, Analysis of the Temperature Dependence of Strain-Hardening Behavior in HighStrength Steel, Metall. Trans., 1989, 20A, p 2819-2829

15. G.E. Dieter, Mechanical Metallurgy, 3rd ed., McGraw-Hill Book Co., New York, 1988, p 287

16. JMatPro V.6.2. User's Manual

17. Y. Li, D.N. Crowther, P.S. Mitchell, and T.N. Baker, The Evolution of Microstructure During Thin Slab Direct Rolling Processing in Vanadium Microalloyed Steels, ISIJ Int., 2002, 42(6), p 636-644

18. J.S. Park, M. Ajmal, and R. Priestner, Tensile Properties of Simulated Thin Slab Cast and Direct Rolled Low Carbon Steel Microalloyed with $\mathrm{Nb}, \mathrm{V}$ and Ti, ISIJ Int., 2000, 40(4), p 380-385

19. C. Shiga, T. Hatomura, J. Kudoh, A. Kamada, K. Hirose, and T. Sekine, Development of Large Diameter High Strength Line Pipes for Low Temperature Services, Kawasaki Steel Technical Report No. 4, 1981, p 97-109

20. P. Choquet, A. LeBon, and C. Perdix, Mathematical Model for Predictions of Austenite and Ferrite Microstructures in Hot Rolling Processes, IRSID Report, St. Germain-en-Laye, France, 1985, p 7

21. F.B. Pickering, Steel Metallurgical Principles: Encyclopedia of Materials Science and Engineering, Vol 6, The MIT Press, Cambridge, 1986

22. N. Kariya et al., High Carbon Hot-Rolled Steel Sheet and Method for Production Thereof. European Patent Application EP 2.103.697 A1, 23 Sept 2009, p 15

23. H.P. Hougardy, Werkstoffkunde Stahl Band 1 - Grundlagen, Verlag Stahleisen GmbH, Düsseldorf, 1984, p 229 [in German]

24. O.G. Kasatkin, B.B. Vinokur, and V.L. Pilyushenko, Calculation Models for Determining the Critical Points of Steel, Met. Sci. Heat Treat., 1984, 26(1-2), p 27-31

25. S.H. Park et al., Development of Ductile Ultra-High Strength Hot Rolled Steels, POSCO Technical Report, 1996, p 50-128

26. J. Trzaska et al., Modelling of CCT Diagrams for Engineering and Constructional Steels, J. Mater. Process. Technol., 2007, 192-193, p 504-510

27. B. Mintz, J.R. Banerjee, and K.M. Banks, Regression Equation for $\mathrm{Ar}_{3}$ Temperature for Coarse Grained as Cast Steels, Ironmak. Steelmak., 2011, 38(3), p 197-203 